\title{
A brazilian amazon: olhares britânicos sobre Maria Quitéria de Jesus
}

\author{
Nathan Gomes ${ }^{1}$ \\ DOI 10.20396/eha.vil4.3366
}

Em 19 de agosto de 1823, o Diario do Governo informou que, no dia 16 daquele mês, havia desembarcado no porto do Rio de Janeiro o navio Leal Português ${ }^{2}$. Dentre a tripulação, estava "o cadete do Batalhão do Imperador, D. Maria de Jesus Medeiros". Tratava-se da mulher que fugiu da fazenda de seu pai no Recôncavo baiano, em setembro de $1822^{3}$, para engrossar as fileiras do chamado Exército Pacificador, formado por milícias das várias vilas da região, que se voltaram contra a Junta Governativa instalada pelas Cortes de Lisboa na Bahia. A peleja ficou conhecida como Guerra de Independência do Brasil na Bahia ${ }^{4}$.

Em 30 de agosto, o mesmo jornal relatava ao público da Corte sobre a participação da jovem baiana na guerra, reproduzindo o ofício de José Joaquim de Lima e Silva, comandante em chefe do Exército Pacificador, à Secretaria de Estado dos Negócios da Guerra:

D. Maria Quitéria de Jesus, natural da Freguesia de S. José das Itapororocas desta Província [Bahia], ao grito da Pátria em perigo, desamparou seus Pais, assentou praça de Soldado, e pegou em armas para sua defesa. Esta mulher tem-se distinguido em toda a campanha com indizível valor, e intrepidez. Três vezes que entrou em combate apresentou feitos de grande heroísmo, avançando de uma, por dentro de um rio com água até aos peitos, sobre uma barca, que batia renhidamente nossa Tropa. O General Labatut conferiu-lhe as honras de $1^{\circ}$ Cadete, e como tal tem sido considerada no Batalhão $N^{\circ} 3$ do Exército Pacificador. Como porém me patenteasse ardentes desejos de beijar a Imperial Mão de S. M. faculteiIhe licença, e parte nesta ocasião para essa Corte. ${ }^{5}$

Durante a estadia de Maria Quitéria na Corte, ela recebeu do imperador a insígnia de cavalei-

\footnotetext{
1 Mestrando pelo Programa de Pós-Graduação em Culturas e Identidades Brasileiras do Instituto de Estudos Brasileiros da Universidade de São Paulo (IEB-USP). Bolsista da Fundação de Amparo à Pesquisa do Estado de São Paulo (Fapesp).

2 Diario do Governo, Rio de Janeiro, 19 de agosto de 1823, n. 41, v. 2. Noticias marítimas, p. 215.

3 REIS JÚNIOR, Pereira. Maria Quitéria. Rio de Janeiro: Ministério da Educação e Cultura, 1953, p. 34.

4 O início da guerra foi em 25 de junho de 1822, quando a Câmara da Vila de Cachoeira aclamou D. Pedro como defensor perpétuo e protetor do Reino do Brasil, um ataque claro à junta de governo à cuja testa estava o Ceneral Madeira de Melo. A guerra terminou em 2 de julho de 1823. quando Madeira e sua tropa abandonaram a cidade de Salvador. Essa é data em que, na Bahia, é comemorada a Independência do Brasil. Ver: KRAAY, Hendrik. Entre o Brasil e a Bahia: As comemorações do Dois de Julho em Salvador, século XIX. Áfro-Ásia. Salvador, n. $23,1999$. 5 SILVA, José Joaquim de Lima. Bahia. Diario do Governo, Rio de Janeiro, 30 de agosto de 1823, n. 51, v. 2, p. 254. (A grafia das palavras foi atualizada, mantendo-se a pontuação e as maiúsculas originais).
} 
ro da Ordem Imperial do Cruzeiro e um soldo de alferes ${ }^{6}$. Uma vez no Rio de Janeiro, Quitéria travou contato com viajantes ingleses que, curiosos com que o deviam classificar como expressão de um nacionalismo malformado7, legaram à posteridade uma série de imagens e relatos sobre a combatente baiana. Fontes que revelam, sobretudo, o modo pelo qual esses ingleses (agentes decisivos no desenrolar do processo) viam Maria Quitéria e as turbulências em torno da emancipação do Brasil.

Certamente um dos primeiros registros sobre Maria Quitéria é um desenho que tem sido atribuído a Henry Chamberlain, possivelmente datado de 1823, e que pertence ao acervo da Pinacoteca do Estado de São Paulo. A baiana é identificada como "uma amazona brasileira" no texto escrito nas margens do desenho. A figura aparece defronte, vestida com a farda azul escura e a mesma saia quadriculada presente na gravura e no diário de Graham ("a tartan kilt"8) por cima da calça branca. A legenda que acompanha o retrato indica que o autor viu Quitéria andando pelas ruas do Rio de Janeiro paramentada assim: "A Brazilian amazon to whom the Emperor gave na Ensign comission, for having been twice wounded in engagements against the Portuguese, she rode $\&$ walked about in this dress [?] at Rio de Janeiro" (imagem 1).

A principal dessas fontes é, sem dúvida, Maria Graham. A escritora inglesa registrou em seu diário que conheceu Quitéria em 29 de agosto de 1823. O relato do encontro veio a público por meio da publicação, em 14 de abril de $1824^{9}$, de Journal of a Voyage to Brazil' ${ }^{\circ}$. O diário veio acompanhado de uma série de gravuras representando a paisagem brasileira gravadas a partir de oito desenhos originais de Graham. As três imagens retratando as gentes do Brasil são de autoria de outro viajante inglês, Augustus Earle. Um terceiro personagem inglês, Edward Finden, que não esteve no Rio, foi gravador de todas essas imagens. Dois trabalhos de Earle representam mercados de pessoas escravizadas, Slave Market at Rio de Janeiro (imagem 2) e Gate \& Slave Market at Pernambuco (imagem 3). Foi justamente em Recife que Maria Graham viu pela primeira vez um mercado dedicado ao comércio de pessoas, o que parece tê-la chocado profundamente ${ }^{11}$.

A terceira colaboração de Earle em Journal of a Voyage to Brazil é um retrato de Maria Quitéria, intitulado Dona Maria de Jesus (imagem 4). A personagem aparece vestindo a emblemática farda

\footnotetext{
6 REIS JÚNIOR, Pereira. Op. cit., p. 57.

7 JANCSÓ, István; PIMENTA, João Paulo G. Peças de um mosaico: ou apontamentos para o estudo da emergência da identidade nacional brasileira. Revista de História das Ideias, Coimbra, v. 21, 2000.

8 GRAHAM, Maria. Journal of a voyage to Brazil, and residence there, during part of the years 1821, 1822, 1823. Londres: Longman, Hurst, Rees, Orme, Brown and Green; ] Murray, 1824, p. 292.

9 PORTO, Maíra Guimarães Duarte. Para inglês ver: uma análise de Journal of a Voyage to Brazil, de Maria Graham. Dissertação (mestrado em história) - Instituto de Ciências Humanas, Universidade de Brasília, Brasília, 2017, p. 22.

10 GRAHAM, Maria. Op. cit

11 "PORTO, Maíra Guimarães Duarte. Op. cit. p. 64.
} 


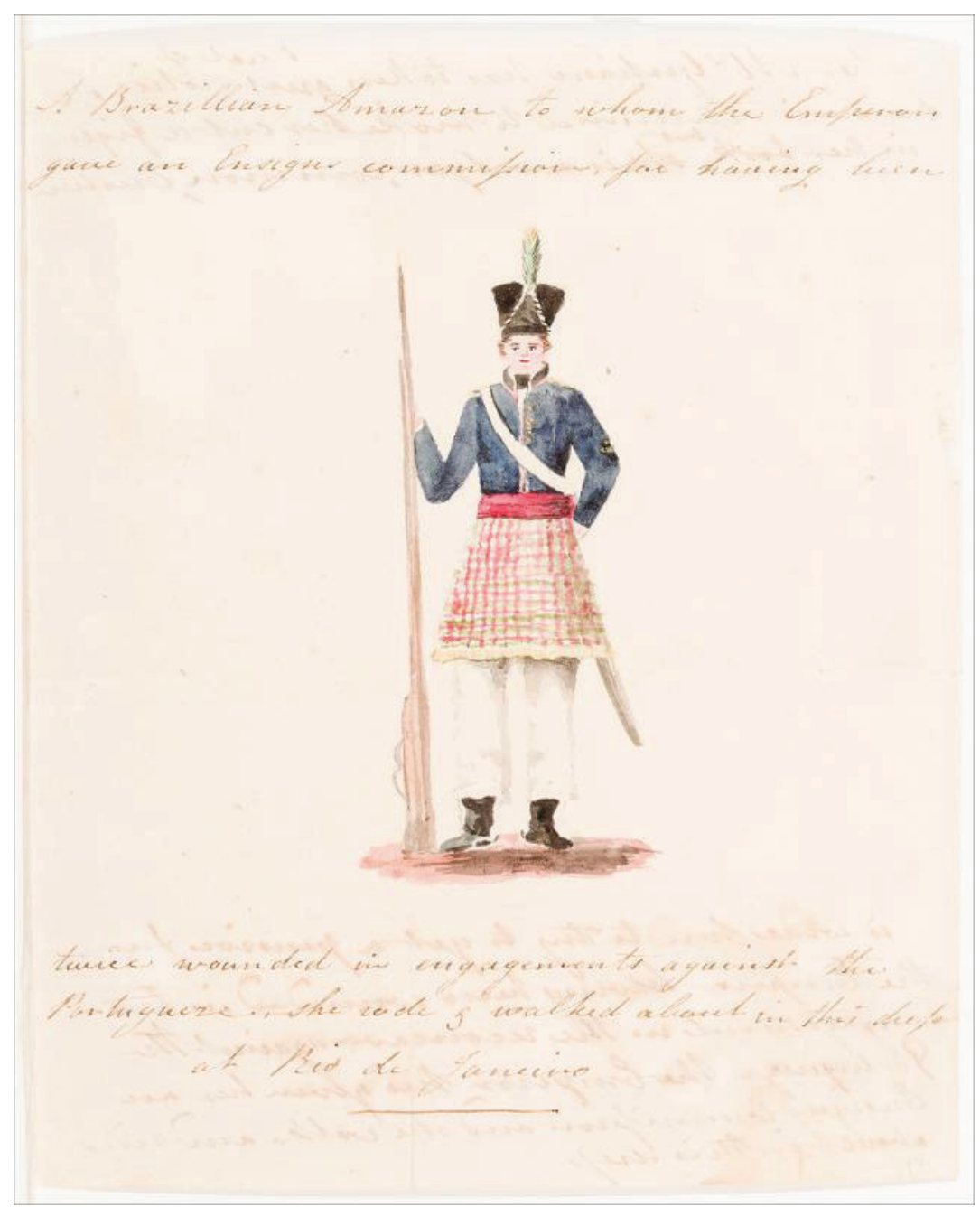

[Figura 01] Henry Chamberlain (atribuído a). A Brazilian amazon, 1823.

$19 \times 15,5 \mathrm{~cm}$, aquarela e grafite sobre papel. Coleção Brasiliana da Pinacoteca do Estado de São Paulo, Brasil. 
[Figura 02]

Augustus Earle (desenhado por); Edward

Finden (gravado por).

Slave Market at Rio de

Janeiro, 1824.

$206 \times 267 \mathrm{~cm}$, água-forte. British Museum, Londres.

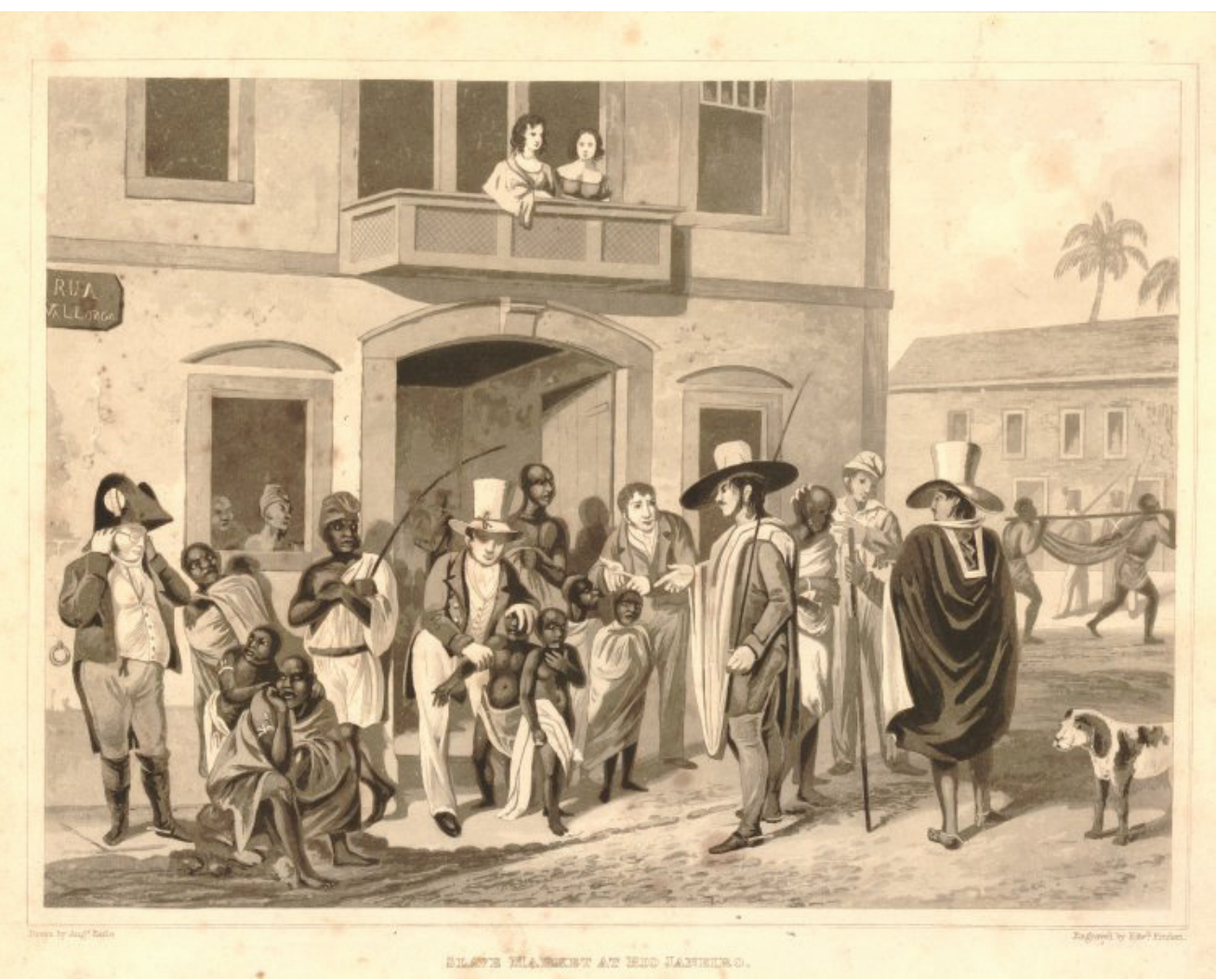

[Figura 03]

Augustus Earle (desenhado por); Edward Finden (gravado por). Gate \& Slave Market at

Pernambuco, 1824.

$199 \times 277 \mathrm{~cm}$, água-forte. British Museum, Londres.

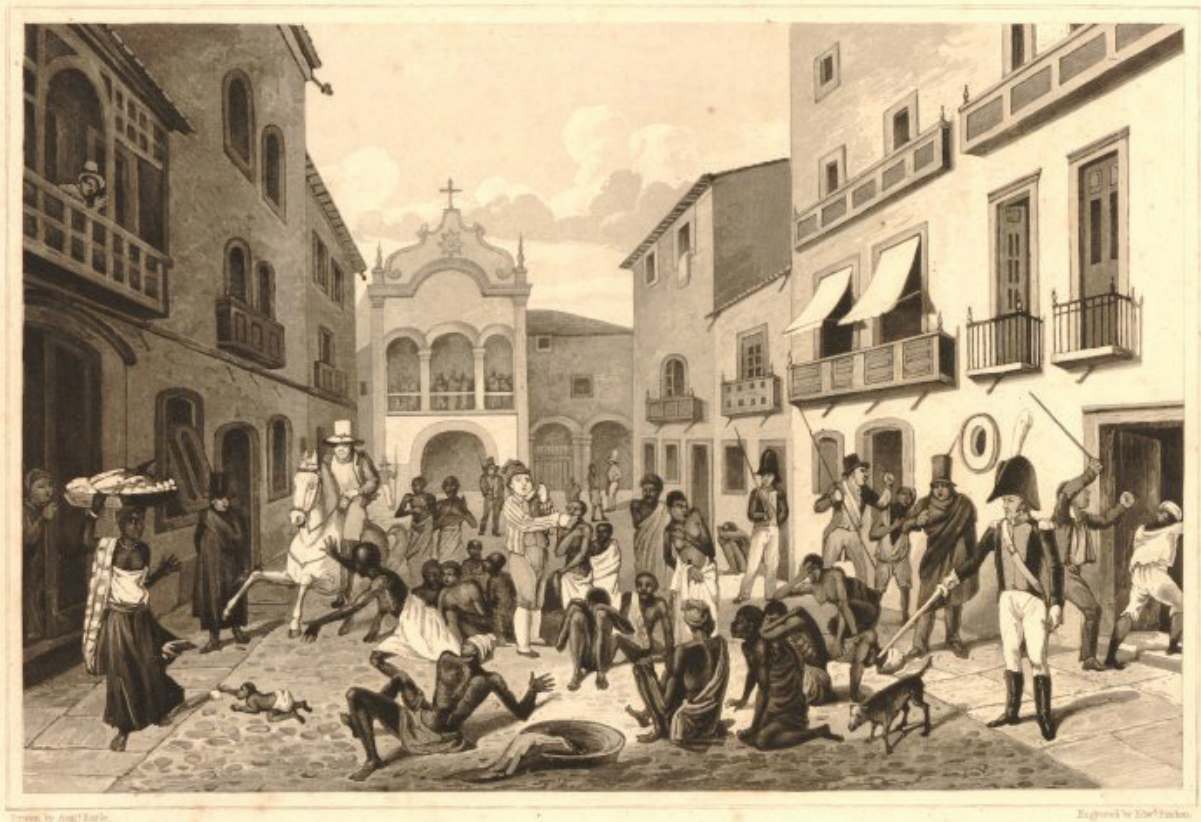


do Batalhão dos Periquitos, com a adição da saia quadriculada ("a tartan kilt"12) por cima da calça branca $^{13}$. Em seu peito esquerdo, vê-se a insígnia da Ordem Imperial do Cruzeiro, distinção extraordinária para uma "mulher militante rebelde"14. Ela segura relaxada sua arma, que está apoiada no chão. Com o corpo inclinado levemente à direita, ela dá um sorriso vago, mirando quem a observa. A figura é enquadrada em meio a uma exuberante paisagem tropical, onde, à beira-mar, ocorrem duas breves cenas bélicas - uma delas, parece se tratar de um fuzilamento.

Maria Graham já era uma escritora profissional quando esteve no Rio de Janeiro (período que se estende entre 1821 e 1824). E é certo que já tinha em mente a publicação do diário quando o escreveu, o que de fato ocorreu logo após seu retorno a Londres (e antes de retornar pela terceira vez ao Brasil). Seu editor era John Murray, que acompanhou durante toda a vida literária, editor também de Lord Byron e Jane Austen ${ }^{15}$. Nesse sentido, por meio dessa publicação, a efígie de Maria Quitéria passou a fazer parte de um circuito global de imagens e mercadorias, cujo centro irradiador era a própria Inglaterra.

Graham havia encomendando ainda no Rio de Janeiro o retrato ao seu conterrâneo, Augustus Earle, conforme registrou em seu diário em 24 de setembro de 1823: "Having now received the portrait which Mr. Erle [sic], an ingenious young English artist, has been painting of the Senhora Alerez [?] Dona Maria de Jesus, I took it to show it to her friend and patron, Jose Bonifacio de Andrada e Silva. [..."16.

Earle, assim como Graham, esteve três vezes no Brasil. A primeira em abril e maio de 1820; a segunda, de janeiro de 1821 ao início de 1824; e a última, de abril a junho de 1832 - viagem essa que se tornou célebre por que o navio HMS Beagle, que o trouxe ao Rio de Janeiro, levava também um tripulante ilustre: o jovem Charles Darwin. Earle, que teve uma formação artística errática ${ }^{17}$, passou quase toda a sua vida a explorar os vários continentes. Sua produção alinha-se, desse modo, a uma tipologia cara à história da arte latino-americana do período, a dos cronistas-viajantes ${ }^{18}$.

\footnotetext{
12 GRAHAM, Maria. Op.cit.p. 292.

13 Ofício do Conselho Interino do Coverno de 28 de março, atendendo à solicitação do General Pedro Labatut, manda que o "Inspetor dos Fardamentos Montarias e Misteres dê a Maria Quitéria com praça de Cadete dois saiotes de Camelão ou outro qualquer pano semelhante, e uma fardeta de Polícia [...]". REIS JÚNIOR, Pereira. Op. cit. s/p. (A grafia das palavras foi atualizada, mantendo-se a pontuação e as maiúsculas originais). 14 PRADO, Maria Ligia Coelho. América Latina no século XIX: tramas, telas, textos. São Paulo: Editora da Universidade de São Paulo; BAURU: Editora da Universidade do Sagrado Coração, 1999, p. 33.

15 PORTO, Maíra Guimarães Duarte. Op. cit. p. 34-35.

16 Tradução livre: "Acabo de receber o retrato que o sr. Earle, um brilhante jovem artista inglês, esteve pintando da Senhora Alerez [?] Dona Maria de Jesus. Eu o levei para mostrar ao seu amigo e padrinho, José Bonifácio de Andrada e Silva. [...]”. GRAHAM, Maria. Op. cit., p. 302.

17 Frequentou informalmente a Royal Academy, em Londres, onde expôs continuamente entre 1806 e 1815. HACKFORTH-Jones, Jocelyn. Augustus Earle travel artist - paintings and drawings in the Rex Nan Kivell Collection National Library of Australia. Londres: Scolar Press, 1980, p. 2.

18 CATLIN, Stanton. O artista-cronista viajante e a tradição empírica na América Latina pós-Independência. In: ADES, Dawn et al. Arte na América Latina: a era moderna, 1820-1980. São Paulo: Cosac \& Naify Edições, 1997, p. 41-61.
} 
Evidência esse caráter errante, é que é na Biblioteca Nacional da Austrália onde está uma parte expressiva da obra brasileira de Earle. Como é o caso da aquarela A female soldier of South America (imagem 5), que parece ser um estudo para o retrato publicado no livro de Graham. Maria Quitéria aparece destacada sob um fundo neutro, enquanto mira o espectador na mesma posição de três quartos do retrato gravado. À exceção dos chumaços cacheados que se sobressaem do capacete, apontando para o fato de que ela cortou seus cabelos ao fugir da casa para a guerra, não há indícios de feminilidade na figura. O rosto tem aspecto marcadamente andrógino. E a vestimenta militar funciona como signo quase inequívoco de masculinidade ${ }^{19}$.

Partindo do pressuposto de que Maria Quitéria posou para o artista, conforme sugere Graham no diário, é bastante provável que seja esse retrato que Augustus Earle "tirou do natural" enquanto tinha defronte a modelo. Comparando-se a aquarela com a gravura publicada em Journal of a Voyage to Brazil, percebem-se as semelhanças na posição da figura e na caracterização do uniforme, o que indica que o primeiro é um estudo para o retrato gravado para o livro. O ponto é que o desenho que teria baseado diretamente o trabalho de Edward Finden é desconhecido. O que me levou a indagar qual seria então o desenho a que Graham se referiu em seu diário. Teria sido a aquarela que está hoje na Austrália? Ou Earle teria produzido um segundo retrato para Graham, esse com mais detalhes e de corpo inteiro?

Guilherme Gonzaga, que dedicou uma dissertação à obra de Earle, afirma que o artista teria produzido dois retratos de Quitéria. Afirmação que ecoa a de Jocelyn Hackforth-Jones, no livro encomendado pela Biblioteca Nacional da Austrália sobre Earle ${ }^{20}$. Contudo, Conzaga é mais preciso que a historiadora australiana ao afirmar que o desenho que serviu de base para a gravura do livro foi entregue por Earle ao seu cunhado, Denis Dighton, que o teria copiado. Essa versão estaria hoje na coleção do Castelo de Windsor, na Inglaterra ${ }^{21}$. Contudo, das 243 entradas relacionadas a Dighton no catálogo online da instituição, nenhuma se refere a Maria Quitéria ou ao Brasil. O que pude encontrar, na verdade, foram quatro desenhos de Earle que foram copiados por Denis Dighton no Museu Britânico, sendo um deles Gate and Slave Market at Pernambuco.

A posição de Conzaga e de Hackforth-Jones vai de encontro a que defende David James, em um artigo pioneiro sobre Augustus Earle. O historiador da arte norte-americano afirma que a obra a

\footnotetext{
19 NOCHLIN, Linda. Representing women. Nova York: Thames and Hudson, 1999, p. 35-37.

20 HACKFORTH-JONES, Jocelyn. Op. cit. p. 74.

21 CONZAGA, Guilherme Goretti. Augustus Earle (1793-1838): pintor viajante: uma aventura solitária pelos mares do sul. Dissertação (mestrado em artes). Departamento de Artes Visuais, Universidade de Brasília, Brasília, 2012, p. 75.
} 

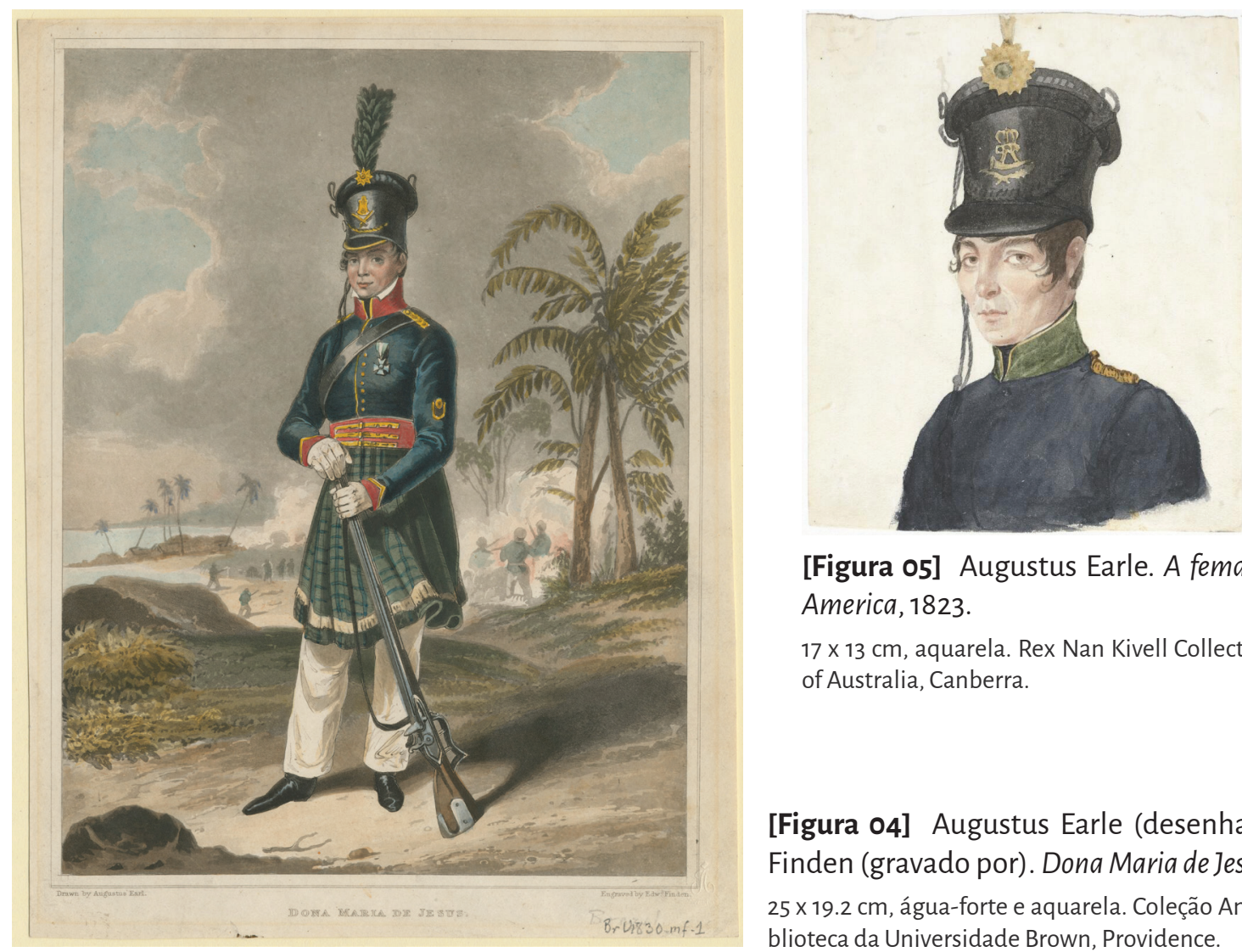

[Figura 05] Augustus Earle. A female soldier of South America, 1823.

17 x $13 \mathrm{~cm}$, aquarela. Rex Nan Kivell Collection, National Library of Australia, Canberra.

[Figura 04] Augustus Earle (desenhado por); Edward Finden (gravado por). Dona Maria de Jesus, 1824.

$25 \times 19.2 \mathrm{~cm}$, água-forte e aquarela. Coleção Anne S. K. Brown da Biblioteca da Universidade Brown, Providence.

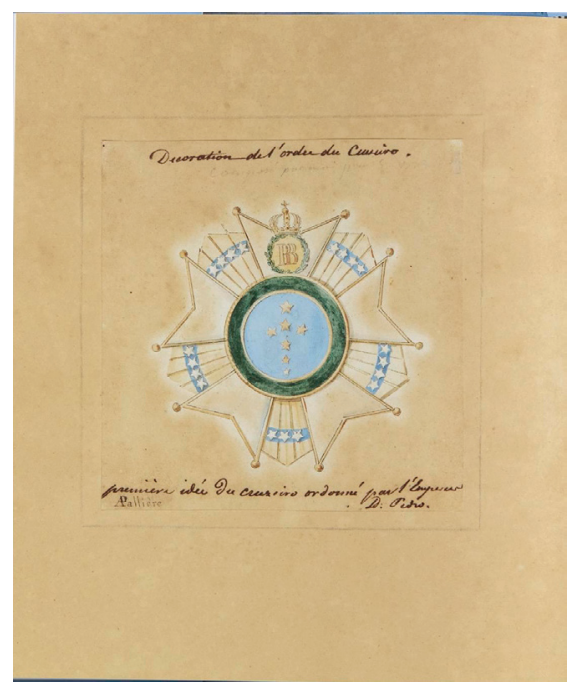

[Figura 06] ]ean-Baptiste Debret. Desenho aquarelado da placa da Ordem Imperial do Cruzeiro, c. 1822.

$10 \times 12 \mathrm{~cm}$, aquarela sobre papel. Museu Imperial, Petrópolis.

[Figura 07]

Denis Dighton. Field Officer. The Duke of York's Creek Light Infantry, 1813. $54 \times 43 \mathrm{~cm}$, aquarela. Royal Collection Trust, Inglaterra.

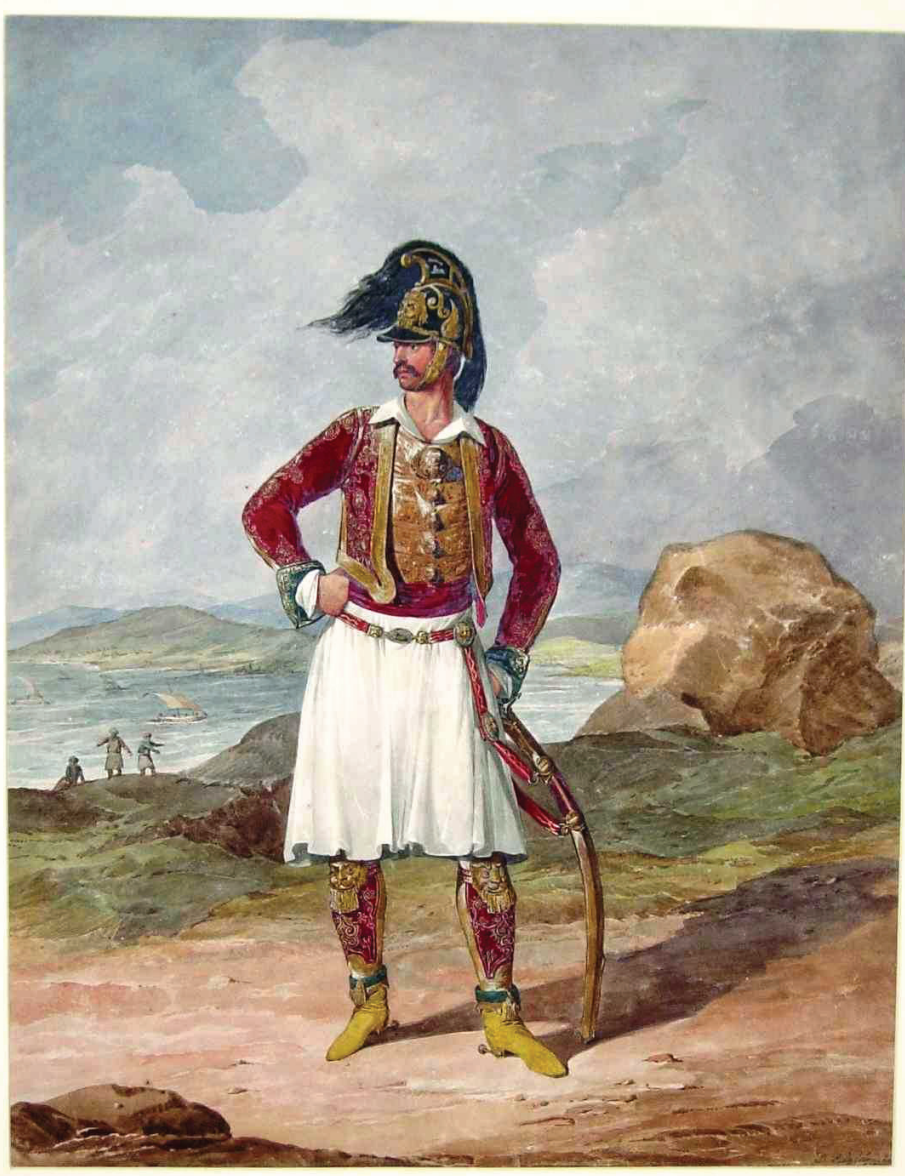


que Maria Graham faz referência no diário tratar-se-ia da aquarela que compõe a coleção Rex Nan Kivell da Biblioteca Nacional da Austrália, a que representa apenas o busto de Maria Quitéria²2.

A posição de James pode ser corroborada a partir de uma análise mais estritamente iconográfica. O caso da insígnia da Ordem Imperial do Cruzeiro, que Maria Quitéria ostenta sob seu peito esquerdo, é interessante nesse sentido. Ao se comparar a que está presente no retrato àquela projetada por Jean-Baptiste Debret (imagem 6), é possível notar que elas guardam grandes diferenças, como o fato de uma ter quatro pontas retas e a outra cinco pontas bipartidas - além da notável ausência do cruzeiro. Supondo-se que Finden tinha às mãos apenas o busto em aquarela de Earle, é possível que ele tenha se valido de algum modelo genérico de insígnia, haja vista que Earle não se ocupou desse detalhe no busto de Quitéria. Curiosamente, esse elemento também está ausente na aquarela atribuída a Henry Chamberlain.

Como no caso da insígnia, não aparece no desenho de Earle nenhuma arma junto à figura. É possível que Edward Finden tenha se baseado também em modelos genéricos para compor a gravura, a fim de suprir esse detalhe. Vale destacar que, mais uma vez, na aquarela atribuída a Chamberlain, Maria Quitéria está armada até os dentes. Não só porta uma arma de fogo com cano longo, como na gravura, mas também uma baioneta e uma espada embainhada na cintura. De fato, ela havia recebido uma espada durante a guerra, conforme o ofício do Conselho Interino do Governo de março de $1823^{23}$.

No retrato gravado por Finden, a figura aparece circunscrita a uma paisagem que remete inequivocamente aos códigos de representação do Novo Mundo. Sobretudo as palmeiras que, logo a partir do segundo plano, espraiam-se por toda a extensão da praia. A configuração do espaço pictórico parece estar alinhada também a certa tipologia de retratos militares, bastante evidente na obra de Denis Dighton, o cunhado de Augustus Earle (imagem 7). As figuras (no caso de Dighton, todas masculinas), fardadas à militar e portando armas brancas ou de fogo, posicionam-se frontalmente ou em três quartos. Seu aspecto heroico é construído pela posição elevada da figura em relação a uma paisagem vasta, que se aprofunda no quadro, isolando o retratado em primeiríssimo plano. Os militares aparecem, assim, dignificados em sua singularidade, como apregoava o tratadista Francisco de Holanda desde o século XVI²4.

\footnotetext{
22 JAMES, David. Um pintor inglês no Primeiro Reinado. Revista do Patrimônio Histórico e Artístico Nacional. Rio de Janeiro, n 12,1955, p. 160.

23 PEREIRA, Reis Júnior. Op. cit., p. 47.

24 FONSECA, Raphael. Francisco de Holanda: "Do tirar pelo natural" e a retratística. Dissertação (mestrado de história). Instituto de Filosofia e Ciências Humanas. Campinas: Unicamp, 2010, p. 56.
} 
Ao aderir a hipótese de que o retrato de Quitéria foi "completado" no processo de edição do livro, em Londres, seria necessário considerar que a contribuição do gravador, Edward Finden, tem um relevo maior do que se costuma atribuir. Assim, seria forçado a estender também ao editor, John Murray, e à própria autora. O problema dessa via de análise é que se apega demasiadamente a aspectos internos às obras e negligencia outros dados importantes.

Um deles é que, na própria gravura, a autoria é descrita de modo a especificar os diferentes papéis na confecção da obra: "Drawn by Augustus Earl [sic]" e "Engraved by Edw.d Finden"25. É assim também que aparece identificada a autoria nas duas gravuras cujo desenho é de Earle e nas oito de Maria Graham publicadas no livro. Pode-se imaginar, portanto, que, se processo envolvido na produção da prancha de Dona Maria de Jesus tivesse divergido das demais, isso seria sinalizado na própria prancha. Dentro do conjunto de obras de Augustus Earle no diário, é possível perceber que pouco foi alterado em relação às imagens matriciais - ainda que interferências dessa ordem fossem frequentes e toleradas ${ }^{26}$ (imagem 8).

Do meu ponto de vista, a hipótese dos dois desenhos é plausível. Não há indícios, por exemplo, que tenha sido Maria Craham a levar A female soldier of South America a Inglaterra. Até onde Jocelyn Hackforth-Jones apurou, o desenho que hoje em dia está na Austrália não foi em nenhum momento propriedade da família Graham ou Calcott ${ }^{27}$, mas da família do próprio Earle ${ }^{28}$, o que indica que foi o artista quem ficou com o estudo após sair do Rio. Além do mais, é preciso considerar que há itens do acervo tanto do Museu Britânico, quanto da Coleção Real, cujos registros não estão disponíveis online. Nesse sentido, não descarto a possibilidade de haver um segundo retrato ainda não revelado pela historiografia. Talvez mesmo a tal cópia produzida pelo cunhado de Earle, Denis Dighton, a que se referiu Conzaga ${ }^{29}$.

A relevância da discussão proposta neste artigo gira em torno do fato de que a gravura no diário de Maria Graham acabou por estabelecer a iconografia de Maria Quitéria ${ }^{30}$. Identificar qual

\footnotetext{
25 Tradução livre: "Desenho por Augustus Earl [sic]" e "Gravado por Edwd Finden".

26 MARTINS, Luciana de Lima. Op. cit. p. 63-66.

27 Em 1827, Graham casou com Sir August Wal Calcott, também artista. A ele é atribuída a doação em 1845 do desenho Slave Market at Rio de Janeiro de Augustus Earle ao Museu Britânico.

28 Até onde Hackforth-Jones apurou, o retrato esteve primeiro com o meio-irmão de Augustus Earle, William Henry Smyth. Passando a seu neto, Herbert Warigton Smyth, que o levou a leilão na Sotheby's em maio de 1926. O arrematante foi Walter Spencer, que o vendeu em seguida a Rex Nan Kivell. Em 1948, o colecionador neozelandês pôs sob custódia da Biblioteca Nacional da Austrália o conjunto de 161 aquarelas e desenhos (e quatro manuscritos). A transferência formal só se concretizou em 1959. G. CHANDLER. Preface. In: HACKFORTH-JONES, Jocelyn. Op. cit. p. V.

29 GONZAGA, Guilherme Goretti. Op. cit. p. 75.

30 Para um desenvolvimento dessa discussão, ver: COMES, Nathan. A la guerra Americanas: questões de gênero e etnicidade nos retratos de Maria Quitéria de Jesus. Revue Interdisciplinaire de Travaux sur les Amériques, Paris, n. 12, set. 2019.
} 
[Figura 08]

Augustus Earle. Slave Market at Rio de Janeiro,

1823.

$183 \times 264 \mathrm{~cm}$, aquarela. British

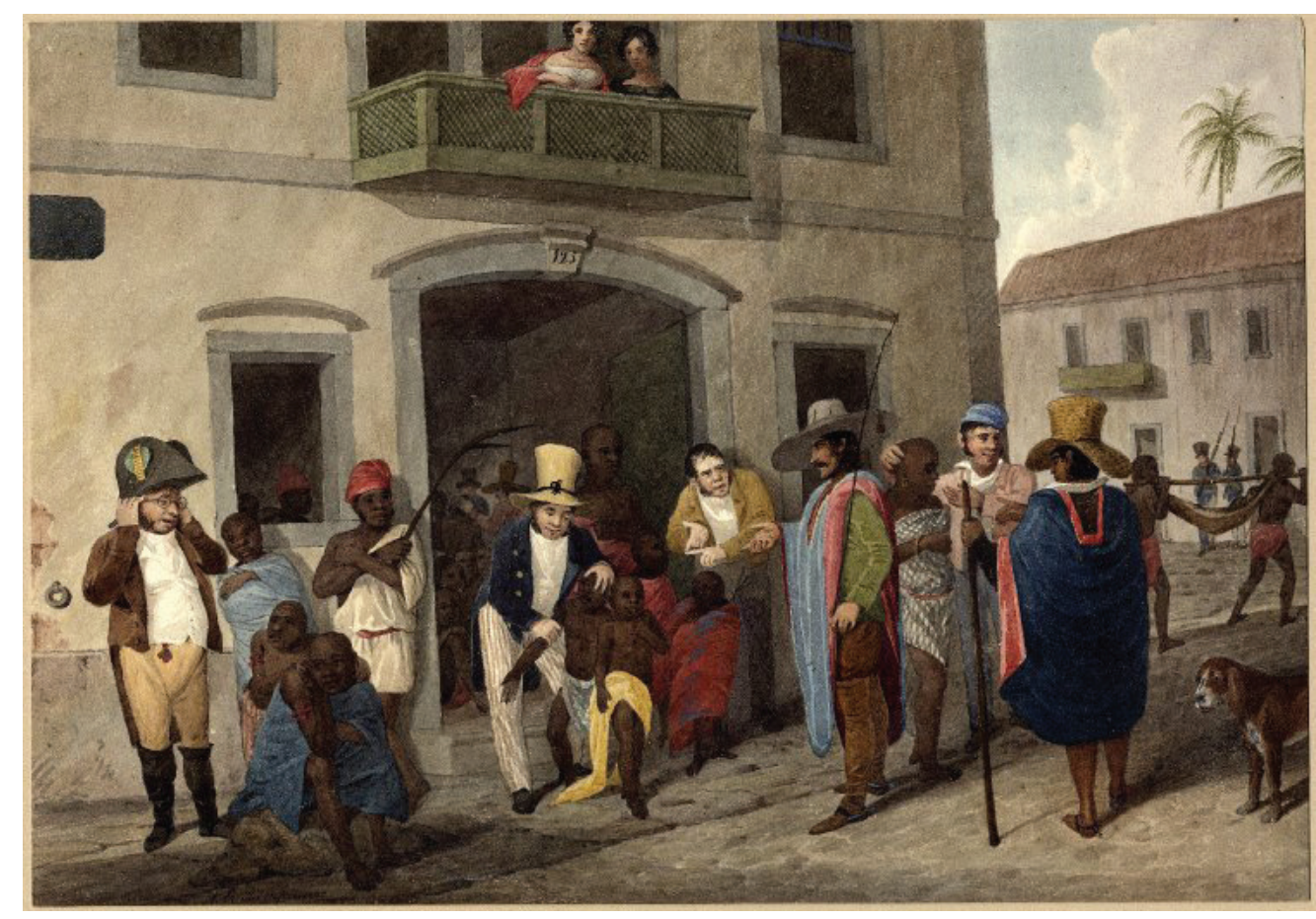

Museum, Londres.

[Figura 09]

Domenico Failutti. Maria Quitéria de Jesus

Medeiros, 1920.

$155 \times 253,5 \mathrm{~cm}$, óleo sobre tela. Museu Paulista da Universidade de São Paulo, São Paulo.

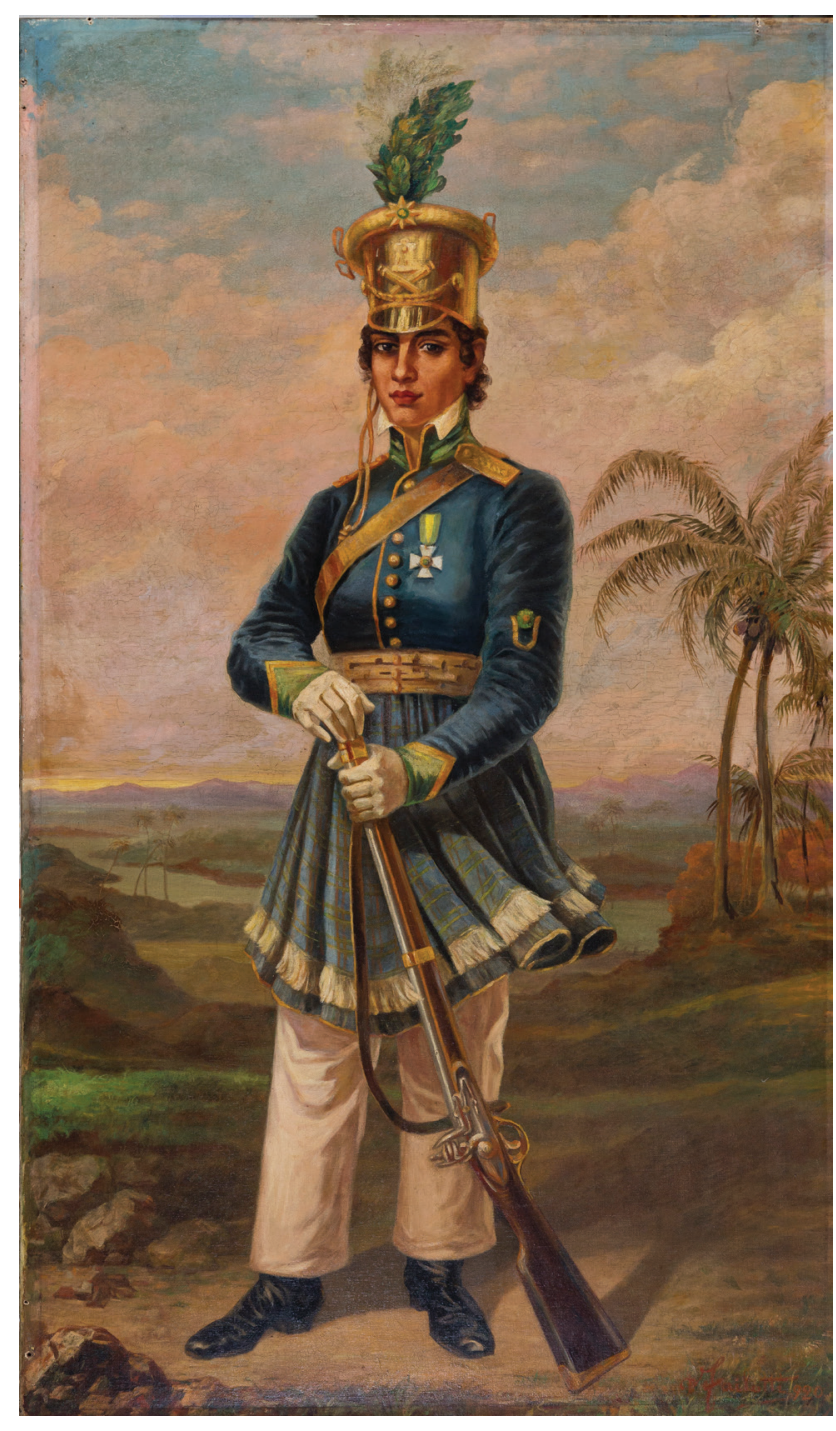


é o fundamento dessa iconografia é uma questão importante no sentido de pensar o papel dos discursos visuais que moldaram certa compreensão do que foi o processo de independência brasileira - e no qual a Inglaterra teve papel de protagonista em vários aspectos.

Affonso Taunay é prova da fortuna que o retrato publicado em Journal of a Voyage to Brazil conquistou cem anos após sua publicação: "reproduziu o Cav. Failutti, em pintura a óleo, a tão conhecida e popular gravura de Miss Graham [sic] representando a heroína baiana da Campanha da Independência, Maria Quitéria de Jesus"31.

Em 1920, às vésperas do Centenário da Independência, Domenico Failutti entregava ao Museu Paulista sua versão para o retrato de Maria Quitéria (imagem 9). O italiano é o mesmo autor dos retratos de Dona Leopoldina e os filhos e de Sóror Joana Angélica, mártir da Guerra de Independência na Bahia ${ }^{32}$. Ele havia recebido a encomenda de Taunay, o demiurgo responsável pelo projeto decorativo que reorientou o museu, transformando-o em um monumento à Independência. Taunay alçou a baiana ao Salão de Honra, onde também deveria ser exposto o retrato da imperatriz (posicionado exatamente do lado oposto ao de Quitéria na galeria), além da monumental Independência ou Morte! de Pedro Américo, que já estava no museu desde 1895.

A efígie da combatente baiana atua, sem dúvida, nas disputas pela conformação da memória nacional, por meio da qual são expressos dois elementos fundamentais: a participação popular e a atuação das mulheres. A exploração desses aspectos históricos, fundamentalmente a partir da iniciativa de Taunay no Museu Paulista, pode ser interpretada como tentativa de alargar, ainda que de modo tímido, o que seria o panteão de heróis nacionais, em que notavelmente predominam os homens brancos, bem formados e de boa família. Por outro lado, foi uma forma eficaz de domesticar a trajetória heterodoxa de uma "mulher militante rebelde", na feliz expressão de Maria Ligia Coelho Prado $^{33}$. Construindo, assim, a memória de Maria Quitéria menos ligada à subversão de gênero e mais próxima de gérmen da nacionalidade brasileira.

\footnotetext{
31 TAUNAY, Affonso d' Escragnolle. Relatório referente ao anno de 1922 apresentado a 23 de Janeiro de 1923 , ao excellentissimo senhor secretário do interior, doutor Alarico Silveira, pelo director em comissão, do Museu Paulista, Affonso d' Escragnolle Taunay. In: Revista do Museu Paulista. São Paulo, tomo XIII, 1926, p. 733.

32 SIMIONI, Ana Paula Cavalcanti; LIMA JÚNIOR, Carlos. Heroínas em batalhas: figurações femininas em museus em tempos de centenário: Museu Paulista e Museu Histórico Nacional, 1922. Museologia \& Interdisciplinaridade s Brasília, v. 7, n. 13, jan./jul. 2018 , p. 31-54.

33 PRADO, Maria Ligia Coelho. Op. cit. p. 33.
} 


\section{Referências bibliográficas}

CATLIN, Stanton. O artista-cronista viajante e a tradição empírica na América Latina pós-Independência. In: ADES, Dawn et al. Arte na América Latina: a era moderna, 1820-1980. São Paulo: Cosac \& Naify Edições, 1997, p. 41-61.

FONSECA, Raphael. Francisco de Holanda: "Do tirar pelo natural" e a retratística. Dissertação (mestrado de história). Instituto de Filosofia e Ciências Humanas. Campinas: Unicamp, 2010

GOMES, Nathan. A la guerra Americanas: questões de gênero e etnicidade nos retratos de Maria Quitéria de Jesus. Revue Interdisciplinaire de Travaux sur les Amériques, Paris, n. 12, set. 2019.

CONZACA, Guilherme Goretti. Augustus Earle (1793 - 1838): pintor viajante: uma aventura solitária pelos mares do sul. Dissertação (mestrado em artes). Departamento de Artes Visuais, Universidade de Brasília, Brasília, 2012.

HACKFORTH-Jones, Jocelyn. Augustus Earle travel artist - paintings and drawings in the Rex Nan Kivell Collection National Library of Australia. Londres: Scolar Press, 1980.

KRAAY, Hendrik. Entre o Brasil e a Bahia: As comemorações do Dois de Julho em Salvador, século XIX. Áfro-Ásia. Salvador, n. 23, 1999.

JAMES, David. Um pintor inglês no Primeiro Reinado. Revista do Patrimônio Histórico e Artístico Nacional. Rio de Janeiro, $\mathrm{n}^{\circ} 12,1955$, pp. 151-169.

JANCSÓ, István; PIMENTA, João Paulo G. Peças de um mosaico: ou apontamentos para o estudo da emergência da identidade nacional brasileira. Revista de História das Ideias, Coimbra, v. 21, 2000, pp. 389-440.

MARTINS, Luciana de Lima. O Rio de Janeiro dos viajantes: o olhar britânico (1800-1850). Rio de Janeiro: Jorge Zahar Editora, 2011.

NOCHLIN, Linda. Representing women. Nova York: Thames and Hudson, 1999.

PORTO, Maíra Guimarães Duarte. Para inglês ver: uma análise de Journal of a Voyage to Brazil, de Maria Graham. Dissertação (mestrado em história) - Instituto de Ciências Humanas, Universidade de Brasília, Brasília, 2017.

PRADO, Maria Ligia Coelho. América Latina no século XIX: tramas, telas, textos. São Paulo: Editora da Universidade de São Paulo; BAURU: Editora da Universidade do Sagrado Coração, 1999.

REIS JÚNIOR, Pereira. Maria Quitéria. Rio de Janeiro: Ministério da Educação e Cultura, 1953.

SIMIONI, Ana Paula Cavalcanti; LIMA JÚNIOR, Carlos. Heroínas em batalhas: figurações femininas em museus em tempos de centenário: Museu Paulista e Museu Histórico Nacional, 1922. Museologia \& Interdisciplinaridade s Brasília, v. 7, n. 13, jan./jul. 2018, p. 31-54. 